Relations industrielles

Industrial Relations

\title{
Mouvements ouvriers et socialistes, l'Amérique latine, par Carlos M. Rama. Les éditions ouvrières, Paris, 1959, 222 pages.
}

\section{Gérald Dion}

Volume 15, numéro 1, janvier 1960

URI : https://id.erudit.org/iderudit/1022089ar

DOI : https://doi.org/10.7202/1022089ar

Aller au sommaire du numéro

Éditeur(s)

Département des relations industrielles de l’Université Laval

ISSN

0034-379X (imprimé)

1703-8138 (numérique)

Découvrir la revue

Citer ce compte rendu

Dion, G. (1960). Compte rendu de [Mouvements ouvriers et socialistes,

l'Amérique latine, par Carlos M. Rama. Les éditions ouvrières, Paris, 1959, 222

pages.] Relations industrielles / Industrial Relations, 15(1), 151-151.

https://doi.org/10.7202/1022089ar

Tous droits réservés (C Département des relations industrielles de l’Université Laval, 1960
Ce document est protégé par la loi sur le droit d'auteur. L’utilisation des services d'Érudit (y compris la reproduction) est assujettie à sa politique d'utilisation que vous pouvez consulter en ligne.

https://apropos.erudit.org/fr/usagers/politique-dutilisation/ 
tions et d'obligations sur le marché des capitaux) vont contribuer à équilibrer le pouvoir des corporations. Mais, à l'heure actuelle, le pouvoir de disposer des placements est entre les mains des sociétés de fiducie. Il faudra inventer d'autres sortes de contrôles qui s'ajouteront à ceux qui existent déjà comme le gouvernement et les syndicats ouvriers.

Pension Funds and Economic Power, comme la plupart des autres rapports publiés par «The Twentieth Century Fund » nous plonge dans un des problèmes les plus importants qu'il $y$ a lieu d'étudier attentivement. Tous ceux qui ont à s'occuper des fonds de pension dans l'industrie doivent connaître cet ouvrage.

M. $L$.

Mouvements ouvriers et socialistes, l'Amérique latine, par Carlos M. Rama. Les éditions ouvrières, $\mathrm{Pa}$ ris, 1959, 222 pages.

Cet ouvrage se situe dans la série des études commencées par Edouard Dolléans et continuées sous la direction de Michel Crozier. Ce n'est pas une histoire, mais une chronologie et une bibliographie. L'auteur présente ici l'Amérique latine. Sous ce titre, il faut inclure non seulement, comme on a l'habitude de le faire, l'Amérique du sud, mais aussi le Mexique, les pays de l'Amérique centrale et des Caraïbes.

Une courte introduction délimite l'objet de cet ouvrage et fournit les grandes lignes qui permettent une vue d'ensemble sur le mouvement d'émancipation des masses laborieuses dans ces pays. L'auteur a ensuite consacré un chapitre à chaque période: a) $1492-$ 1700 , époque de la découverte et de la conquête; b) 1700-1809, la société coloniale au XVIIe siècle; c) 18101862 , les révolutions qui amènent l'indépendance et l'introduction de l'économie capitaliste; d) 1862-1917, l'émigration populaire reuropéenme avec l'apparition du syndicalisme et des courants socialistes; e) 1918-1936, l'époque contemporaine. Cet ouvrage s'arrête donc avec la révolution espagnole parce que, depuis cet évé nement, il est possible de trouver des ouvrages spécialisés.
L'auteur procède de la façon suivante: chaque chapitre est composé d'une chronologie des événements suivie d'une bibliographie comprenant les ouvrages, les brochures, les documents et les journaux. Il a fait oeuvre de pionnier avec cette recherche globale. Son travail est extrêmement utile à tous ceux qui désirent avoir une vue rapide sur la naissance et le développement des mouvements populaires comme aussi aux autres qui voudront poursuivre des études particulières sur chacun des pays.

G. D.

\section{Labour Relations Trends, Retrospect and Prospect, Industrial Relations Centre, McGill University, Mont- real, 1959, $102 \mathrm{pp}$.}

Il s'agit du rapport du dixième congrès annuel des relations industrielles organisé par McGill. Ces assises, qui évoquaient le dixième anniversaire de la Loi sur les relations industrielles et sur les enquêtes visant les différends du travail et de la fondation du Industrial Relations Centre de McGill. avaient pour but de faire le point de la situation et d'envisager les principales perspectives d'avenir dans le domaine des relations patronales-ouvrières.

La première communication, par $\mathbf{H}$. D. Woods, directeur du Centre, porte principalement sur la structure de l'intervention gouvernementale et ses effets sur la négociation collective, notamment en ce qui concerne l'accréditation des syndicats et la sécurité syndicale.

Un deuxième texte, préparé par Bora Laskin, traite de l'arbitrage. L'auteur y étudie certains aspects légaux, par exemple l'admissibilité de la preuve, la comparution des témoins, les précédents, etc. Il aborde aussi le problème des droits de la gérance et ses répercussions sur l'attitude des arbitres.

Frederick Harbison parle ensuite des relations industrielles aux EtatsUnis. Après avoir brossé à grands traits le tableau de la situation, il insiste sur le fait que le grand problème de demain sera celui des cadres. Les préposés aux relations industriel- 